OPEN ACCESS

Edited by:

Jochen Ait Mueller,

Helmholtz Centre for Environmental

Research, Germany

Reviewed by:

Dimitris tsaltas,

Cyprus University of Technology,

Cyprus

Joseph Henry Vineis,

Marine Biological Laboratory, USA

*Correspondence:

Marcin Łoś

marcin.los@biol.ug.edu.pl

Specialty section:

This article was submitted to

Systems Microbiology,

a section of the journal

Frontiers in Microbiology

Received: 15 April 2016

Accepted: 08 August 2016

Published: 09 September 2016

Citation:

Zielińska S, Kidawa $D$

Stempniewicz L, Łoś M and Łoś JM (2016) The Arctic Soil Bacterial Communities in the Vicinity of a Little Auk Colony. Front. Microbiol. 7:1298. doi: 10.3389/fmicb.2016.01298

\section{The Arctic Soil Bacterial Communities in the Vicinity of a Little Auk Colony}

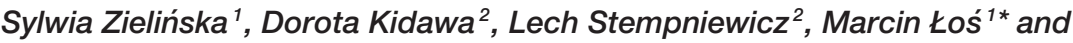 \\ Joanna M. Łos' ${ }^{1}$
}

${ }^{1}$ Department of Molecular Biology, University of Gdansk, Gdansk, Poland, ${ }^{2}$ Department of Vertebrate Ecology and Zoology, University of Gdansk, Gdansk, Poland

Due to deposition of birds' guano, eggshells or feathers, the vicinity of a large seabirds' breeding colony is expected to have a substantial impact on the soil's physicochemical features as well as on diversity of vegetation and the soil invertebrates. Consequently, due to changing physicochemical features the structure of bacterial communities might fluctuate in different soil environments. The aim of this study was to investigate the bacterial assemblages in the Arctic soil within the area of a birds' colony and in a control sample from a topographically similar location but situated away from the colony's impact area. A high number of OTUs found in both areas indicates a highly complex microbial populations structure. The most abundant phyla in both of the tested samples were: Proteobacteria, Acidobacteria, Actinobacteria, and Chloroflexi, with different proportions in the total share. Despite differences in the physicochemical soil characteristics, the soil microbial community structures at the phylum level were similar to some extent in the two samples. The only share that was significantly higher in the control area when compared to the sample obtained within the birds' colony, belonged to the Actinobacteria phylum. Moreover, when analyzing the class level for each phylum, several differences between the samples were observed. Furthermore, lower proportions of Proteobacteria and Acidobacteria were observed in the soil sample under the influence of the bird's colony, which most probably could be linked to higher nitrogen concentrations in that sample.

Keywords: bacterial community structure, Arctic soil, $16 \mathrm{~S}$ rRNA gene, NGS, Alle alle

\section{INTRODUCTION}

The high Arctic archipelago of Svalbard, with Spitsbergen being the largest island, is a breeding ground for many seabirds, including the little auk (Alle alle) which is considered to be the most numerous seabird species in the Palearctic. The little auk population in Hornsund exceeds one million members and is one of the largest colonies in the world (Isaksen, 1995). Birds arrive at this colony area in large numbers in mid-April and stay there until late August (Stempniewicz, 2001). Marine birds that forage at sea and breed on land deposit large amounts of guano, eggshells, feathers, and carcasses near their colonies. This large-scale transport of organic and inorganic matter from the sea to the land is crucial for many Arctic and Antarctic terrestrial ecosystems (Stempniewicz et al., 2007; Zwolicki et al., 2015). It was previously shown that the guano 
deposition influences various physical and chemical soil parameters and enhances the formation of ornithogenic soils, thereby facilitating the development of associated terrestrial plant communities (Stempniewicz et al., 2007; Zwolicki et al., 2013; Wojciechowska et al., 2015). It has been also shown that abundance of the soil invertebrates, such as springtails (Collembola) or water bears (Tardigrada), is higher in the areas of ornithogenic enrichment of the soil (Zawierucha et al., 2015; Zmudczyñska-Skarbek et al., 2015b). There are several studies denoting a considerable impact of the large seabird colonies on the soil properties in the nutrient-deprived Arctic ecosystems (e.g., Croll et al., 2005; Zwolicki et al., 2013, 2015; Skrzypek et al., 2015). Similarly, birds' contribution to the fertilization of the coastal waters in the vicinity of the colonies has also been denoted (Zelickman and Golovkin, 1972; Zmudczyñska-Skarbek et al., 2015a). Nonetheless, the influence of bird-derived soil fertilization on the structure and abundance of microorganisms has not been reported so far in the Arctic environment. Since the little auks may have a substantial impact on the soil environment, diversity in the Arctic soil bacterial communities within this colony's vicinity could be expected.

Due to harsh environmental conditions, microbial communities in the Arctic soil were expected to be comprised of a relatively low number of bacterial species, but in fact they are as diverse as those found in other biomes (Neufeld and Mohn, 2005; Koyama et al., 2014). Diversity of the Arctic soil bacterial communities can be influenced by various natural factors. The vicinity of a large breeding colony of planktivorous seabirds, the little auks, seems to have a substantial impact on the soil environment (Zwolicki et al., 2013). It was also reported that the ornithogenic soils which arose in the areas of the Adèlie Penguin rookeries in the Ross Sea region of the Antarctica, are characterized with a higher microbial biomass than the mineral soils of the Ross Sea region where the penguins were absent. These soils are also characterized by a higher organic carbon content and higher total nitrogen and phosphorus, with high electrical conductivity and large variations in $\mathrm{pH}$ (Aislabie et al., 2009). Likewise, at the King George Island, the seabird colonies were reported to affect the soil properties and vegetation (Zwolicki et al., 2015). Therefore, the aim of this study was to compare, by using the Next Generation Sequencing (NGS) in $16 \mathrm{~S}$ rRNA gene analysis, the bacterial communities in the soil samples originating from two areas: (1) in the vicinity of a seabird colony and (2) not influenced by seabirds. The samples being compared were collected from topographically similar locations. Since bacterial communities might vary due to external factors affecting the soil environment such as physicochemical conditions, different bacterial communities may be expected in each soil sample. These differences might span the entire community structure, or be limited only to the single phyla present.

\section{MATERIALS AND METHODS}

\section{Study Area and Sample Collection}

Soil samples were collected in the north part of the Hornsund fiord (SW Spitsbergen; $77^{\circ} 0^{\prime} \mathrm{N}, 15^{\circ} 33^{\prime} \mathrm{E}$ ) at the beginning

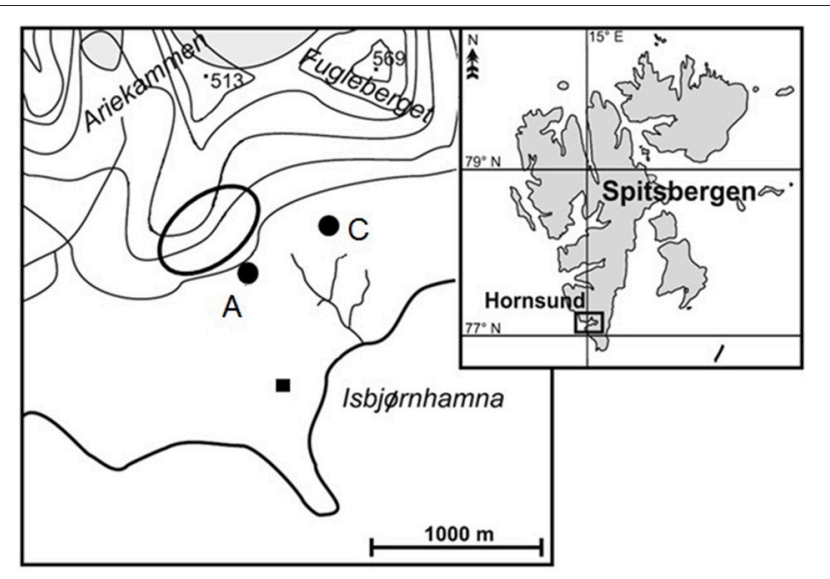

FIGURE 1 | Maps of the study area. Right: Location of the Hornsund fiord at the Spitsbergen. Left: Close-up of the north part of the Hornsund fiord with Ariekammen and Fugleberget; black square - the Polish Polar Station, black oval frame-the little auk colony, black spots - soil sampling sites: A-the area within the little auks colony, and $\mathrm{C}$-the control area away from the routine flight route of the seabirds.

of August 2013 (Figure 1). One of the samples (A)uk was collected in the area influenced by a large breeding colony of planktivorous little auks down the slope, at the edge of the colony. This colony was situated on the Ariekammen mountain slope and consisted of ca. 15,000 breeding pairs (Puczko and Stempniewicz, 2013).. Lush vegetation, with predominating Deschampsia alpina, Prasiola crispa, Cerastium arcticum, and Chrysosplenium tetrandum covered ca. $95 \%$ of this well-fertilized area (Zmudczyñska et al., 2012). Sample (C)ontrol was collected in a topographically similar location (ca $550 \mathrm{~m}$ from the sample A), but away from the routine seabird flight route, hence experiencing only a negligible ornithogenic impact. Vegetation in the control area had a much lower total coverage (ca. 10\%) and was almost entirely represented by a Sanionia uncinata-Salix polaris community (Zmudczyñska et al., 2012). Both samples were collected from the upper $15-20 \mathrm{~cm}$ of the soil, frozen $0.5 \mathrm{~h}$ after collection and stored at $-20^{\circ} \mathrm{C}$ until further analysis.

\section{Physical and Chemical Analysis of the Soil Samples}

Soil physicochemical features were measured according to methodology described by Zwolicki et al. (2013). The soil dry mass (\%) was assessed, as well as the soil conductivity ( $\mu \mathrm{S}$ $\left.\mathrm{cm}^{-1}\right), \mathrm{pH}$ and nitrogen $\left(\mathrm{NO}_{3}^{-}\right.$and $\left.\mathrm{NH}_{4}^{+}\right)$and phosphate $\left(\mathrm{PO}_{4}^{3-}\right)$ content.

\section{DNA Extraction and Bacterial 16S rRNA Gene Amplification}

After thawing, the DNA was extracted from each soil sample (extraction done in triplicate for each sample) using the FastDNA ${ }^{\circledR}$ SPIN Kit for Soil and the FastPrep ${ }^{\circledR}$ Instrument (MP Biomedicals, Santa Ana, CA). To avoid cross contamination of the samples, the whole process was performed using sterile equipment. The quantity and 
quality of the extracted DNA was evaluated by using a Nano Drop spectrophotometer followed by agarose gel electrophoresis. The DNA was stored at $-20^{\circ} \mathrm{C}$ until further use.

The V3-V4 hypervariable regions of bacterial 16S rRNA gene were amplified, using the following primer pair: 341F-CCT ACGGGNGGCWGCAG and 785R-GACTACHVGGGTATC TAATCC. The targeted gene regions have been shown to be the most suitable for Illumina sequencing (Klindworth et al., 2013). Each sample was amplified with NEBNext ${ }^{\circledR}$ High-Fidelity 2xPCR Master Mix (New England BioLabs) according to the manufacturer's instructions. Paired-end (PE, $2 \times 250 \mathrm{nt})$ sequencing was performed with an Illumina MiSeq (MiSeq Reagent kit v2) by the Genomed company (Warsaw, Poland) and following manufacturer's run protocols (Illumina, Inc., San Diego, CA, USA).

\section{Sequencing Data and Statistical Analyses}

The data obtained for the 3 replicates of the DNA extraction for each soil sample were merged and considered as one sample in further taxonomic analysis. The intention of this procedure was to obtain a more reliable view of the bacterial communities' structure. The samples were processed and analyzed by using the Quantitative Insights Into Microbial Ecology (Qiime) pipeline v 1.8.0 software (Caporaso et al., 2010). Low quality paired end $(\mathrm{PE})$ reads were discarded from further analysis and the quality-filtered reads were merged based on the overlap of the PE read with the use of fastq-joint (Aronesty, 2011). The remaining sequences that did not meet the quality criteria were removed from further analysis. Clustering of the operational taxonomic units (OTUs) at the $97 \%$ similarity was performed by using the uclust method (Edgar, 2010). OTUs were assigned to taxa by using GreenGenes v13_5 as a reference (McDonald et al., 2012). The chimera sequences were detected with the use of the Chimera Slayer tool (Haas et al., 2011). After sequence count normalization, statistical analysis was performed on the bacterial and archaeal composition. The diversity indices were estimated based on clusters, including the Chaol, Shannon, and Simpson indices. The NGS data are deposited and fully available under the following study accession numbers: PRJEB9513 and PRJEB9514, at ENA - the European Nucleotide Archive.

The pairwise comparison of the two soil samples A and C, was done using the SIMPER (Similarity Percentage) method based on the Bray-Curtis similarity measure. SIMPER is a simple method for assessing which phyla are primarily responsible for an observed difference between samples (Clarke, 1993). The Bray-Curtis similarity measure (multiplied by 100) is commonly used with SIMPER. Also, the Bray-Curtis similarity is a popular similarity index used for abundance data (Bray and Curtis, 1957). The overall average dissimilarity was computed using all of the phyla, while the phylum-specific dissimilarities were computed for each phylum individually. The chi-square test was performed to examine the differences between the samples, and the samples were compared considering the phylum level. All analyses were done using the PAST 3.0 software (Hammer et al., 2001).
TABLE 1 | Values for the soil ion content (mg/kg soil dry mass), $\mathrm{pH}$, conductivity $(\mathrm{mS} / \mathrm{cm})$ and dry mass $(\%)$ for samples A and C.

\begin{tabular}{lcc}
\hline Parametres/Sample ID & A & C \\
\hline $\mathrm{PO}_{4}^{3-}$ & 23.61 & 1.842 \\
$\mathrm{NO}_{3}^{-}$ & 43.18 & 5.768 \\
$\mathrm{NH}_{4}^{+}$ & 3.575 & 1.496 \\
$\mathrm{pH}$ & 6.51 & 6.74 \\
Conductivity & 113.9 & 61.7 \\
Dry mass & 66.28 & 97.64 \\
\hline
\end{tabular}

\section{RESULTS}

\section{Physical and Chemical Soil Features}

Clear differences in the measured ion concentration and soil conductivity, as well as in the soil dry mass, could be seen between samples A and C (Table 1), as it was previously reported by Zwolicki et al. (2013). Sample A showed much higher content of phosphates (over 12-fold) and nitrates (over 7-fold) when compared to sample $\mathrm{C}$. The $\mathrm{pH}$ of sample A was lower when compared to sample $\mathrm{C}$ (6.51 and 6.74 respectively).

\section{General Description of the Sequencing Results}

From the soil sample A, collected within the little auk colony, we obtained 230,253 good quality 16S rRNA gene sequences (V3-V4 region), while 279,122 gene sequences were obtained from the control sample C. At the phylum level, in case of both samples we were able to classify more than $99.97 \%$ of all of the obtained sequences. A detailed taxonomic analysis on different ranks, for both soil samples, is presented in sunburst charts (Presentation 1) and in a table (Supplementary Table 1). 3600 OTUs were obtained for sample A, and 4844 OTUs for sample C; both of the tested samples had 2822 OTUs in common. The Shannon index value for sample A was 8.92, and 9.31 for sample C, while the Chaol index value was 4391 and 5496, respectively. The Simpson index value was 0.99 for both of the tested samples. The diversity indices represent a randomly selected subset for a sample normalized to 229,213 sequences. The analysis of sample similarity was done on the relatively high taxonomic level due to fact, that we were unable to identify microorganisms on lower taxonomic levels and unclassified microorganisms contributed even up to $80 \%$ of total community share. Additionally, our main goal was to present global analysis and differences between two locations with differences in soil features. The attempt to compare samples on lower phylogenetic level would result in a fragmented picture, not necessary reflecting the global difference in microbial communities.

\section{Microbial Community Composition}

The analysis of bacterial communities found in the soil sample collected within the little auk colony showed that $99.99 \%$ of the total reads were affiliated with Bacteria and $0.01 \%$ with Archaea (Presentation 1). In the control soil sample, the total reads representing Bacteria constituted $99.96 \%$ and 
Archea $0.04 \%$ (Presentation 1). Taxonomy-based analysis of both samples indicated that the soil bacterial communities consisted of 34 phyla of which 32 were represented in both samples (Presentation 1, Supplementary Table 1). Sample A was characterized by a lack of the GN04 and Thermi phyla, while in sample C no Lentisphaerae and WS4 were found. The combined share of those phyla was less than $0.022 \%$ of the total community for each tested sample.

The most abundant phyla found in sample A were: Proteobacteria, Acidobacteria, Actinobacteria, and Chlorofelxi (Figure 2, Table 2). Combined these phyla accounted for more than $72.5 \%$ of the total bacterial sequences obtained. Moreover, 16 of those phyla were responsible for $99.5 \%$ of the total bacterial community. In sample $\mathrm{C}$, the most abundant phylum was Actinobacteria. Other phyla with a significant share were: Chloroflexi, Proteobacteria, and Acidobacteria (Figure 2, Table 2). These phyla jointly accounted for more than $79 \%$ of the total bacterial sequences obtained. In this case, 17 of those phyla were responsible for more than $99.5 \%$ of the total bacterial population. When comparing both samples, sample $\mathrm{C}$ contains almost twice as high abundance of Actinobacteria than sample A, whereas for the Chloroflexi phylum, the difference in abundance between the two samples was only minor. In the case of Proteobacteria and Verrucomicrobia, their higher abundance in the bacterial community structure is related to lower soil $\mathrm{pH}$ and higher nitrogen distribution. The share of Actinobacteria and Proteobacteria was the factor that mostly contributed to the differences between the samples (Table 2). Considering the share of each phylum in the total bacterial composition, the only significant differences between the two samples were observed when comparing the share of Actinobacteria $\left(\chi^{2}=\right.$ 8.91, $d f=1, p=0.004)$. Furthermore, lower proportions of Proteobacteria and Acidobacteria were observed in the soil sample collected within the bird colony than in the control sample, however, these differences were found to be statistically insignificant $\left(\chi^{2}=3.72, d f=1, p=0.054\right.$ and $\chi^{2}$ $=0.60, d f=1, p=0.44$, respectively). Considering all phyla at once, the Bray-Curtis distance measure indicated $78 \%$ similarity between the two samples (A and C) and the chi-square test did not indicate a statistically significant difference between the samples $\left(\chi^{2}=13.09, d f=36\right.$, $p=1.0)$.

At the class level, the two samples differed significantly $\left(\chi^{2}=191.64, d f=85, p<0.0001\right)$. In sample A, the most abundant bacteria were: Betaproteobacteria, Alphaproteobacteria, Chloracidobacteria, and Thermoleophilia. In contrast, Thermoleophilia, Actinobacteria, Alphaproteobacteria, and Chloracidobacteria were the most dominant classes in sample C (Presentation 1, Supplementary Table 1). Betaproteobacteria constitute the highest portion in sample A, with their share amounting to more than $13 \%$. However, we can observe in the control sample that their share is reduced and amounts to only $4.5 \%$ of the total population. Additionally, distribution of Thermoleophilia and Actinobacteria seems to be reduced in soils with lower $\mathrm{pH}$ and increased nitrogen ion concentration. At the class level, only Alphaproteobacteria share a similar proportion

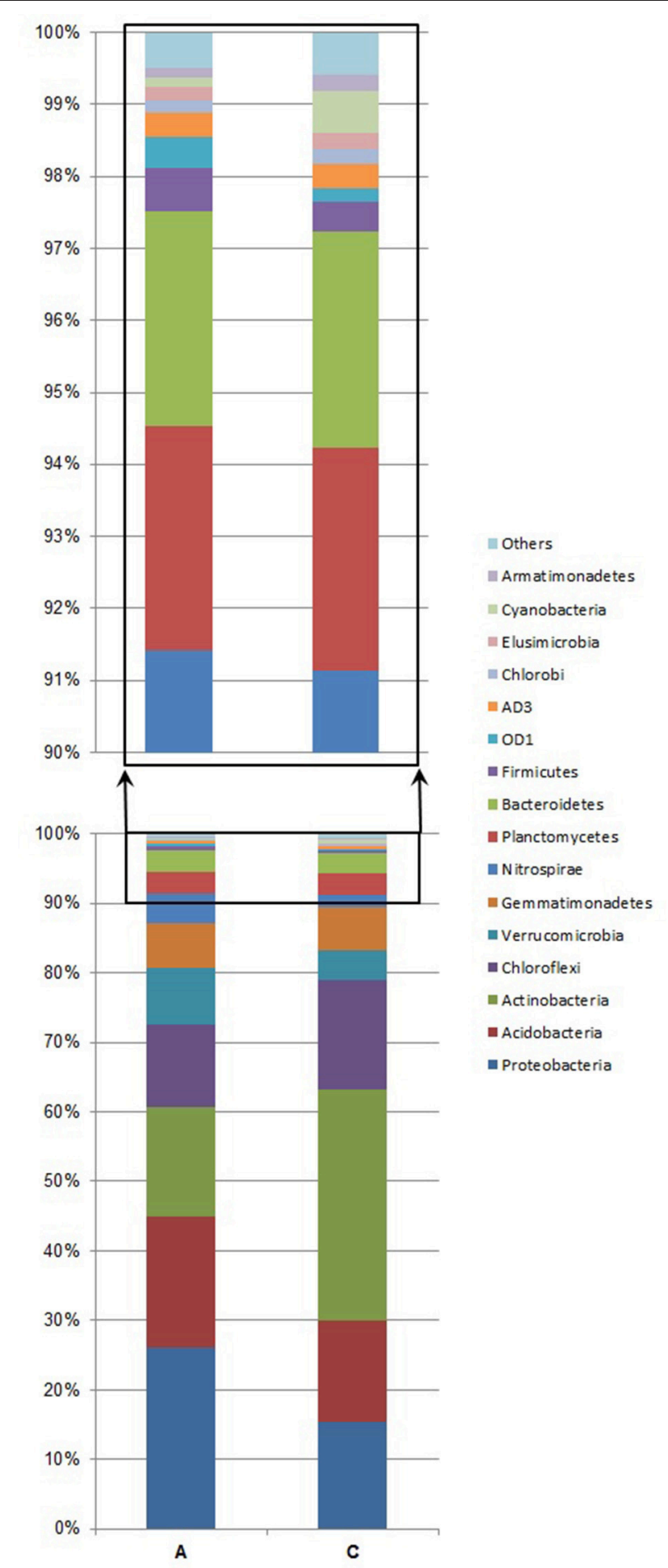

FIGURE 2 | Abundance of bacterial 16S rRNA gene sequences at the phylum level. Analysis of microbial community structure in the soil sample under the little auk' colony influence $(A)$ and in the area away from the routine flight route of birds, treated as a control sample (C). "Others" denotes the following: WS3, TM7, OP11, WS2, TM6, WPS-2, FBP, BRC1, WS4, BHI80-139, NKB19, Fibrobacteres, GN02, OP3, Spirochaetes, Chlamydiae, Lentisphaerae, PAUC34f, GN04, [Thermi], and unassigned. 
among the most abundant bacteria in both tested samples, despite the change in $\mathrm{pH}$ and availability of nitrogen. Additional chi-square test analysis, comparing samples $\mathrm{A}$ and $\mathrm{C}$ at the class level within each phylum separately, indicated significant differences between the samples for five phyla: Actinobacteria, Armatimonadetes, Cyanobacteria, Gemmatimonadetes, and Proteobacteria (Supplementary Tables 1, 2; Figure 3).

\section{DISCUSSION}

Seabird guano is one of the three major nitrogen sources in the polar terrestrial ecosystems, however the tundra fertilization by seabirds is unevenly distributed over time and space as a consequence of patchy distribution of bird colonies and their short breeding period. As was shown previously, deposition of nutrient-rich guano by little auks considerably changes the physicochemical parameters of the soil in the vicinity of the bird colony (Zwolicki et al., 2013). However, despite striking differences in physicochemical soil characteristics, as well as differences in vegetation structure and invertebrates abundance (Wojciechowska et al., 2015; Zawierucha et al., 2015; Zmudczyñska-Skarbek et al., 2015b), we did not find substantial differences at the phylum level of taxonomic ranks in the soil microbial communities in the two samples tested. The similarity between these two tested bacterial communities was $78 \%$, and in addition, the chi-square test did not indicate a statistically significant difference between the samples tested. Still, Actinobacteria and Proteobacteria were responsible for the differences between the samples and further analysis considering each phylum separately indicated that significant differences between the tested samples were specifically found within the Actinobacteria phylum.

High number of OTUs, as well as high values of microbial diversity indexes (the Shannon's and Simpson's indexes), suggest a high number of species in both tested samples. Moreover, the high number of OTUs observed in both samples indicates that both soil microbial communities are highly complex. Rarefaction trends analysis indicated that the sampling of bacterial communities were close to complete, which indicates sufficient efficiency of the DNA extraction method (Supplementary Figure 1). Furthermore, we obtained 2822 OTUs that both samples have in common, which indicates a high similarity between the tested samples. However, there is also a large group of OTUs that are specific for each particular soil sample. Sample $\mathrm{C}$ is characterized by a higher number of OTUs. It seems that more alkaline conditions and impecunious nutrient content in the control area correspond to a more diversified microbiome composition.

As sample A origins from an area strongly influenced by seabirds, it could be expected to contain a less diverse and thus more specialized groups of bacteria than the control sample (Koyama et al., 2014). Still, the most abundant phyla, in both tested samples, were: Proteobacteria, Acidobacteria, Actinobacteria, and Chloroflexi, with varying proportion in the total share between the samples. Such abundance and composition of share in bacterial communities is common for most soil samples of different origin studied so far (Janssen, 2006), including the Arctic soil (Chu et al., 2010). Also, minor groups of the bacterial community structure were similar to other groups previously described for the Arctic soil (Chu et al., 2010; Kim et al., 2014). Until recently, microbial communities in the Arctic soil were expected to have a low level of bacterial species, but in fact they are characterized by an equivalent level of diversity as other biomes are (Koyama et al., 2014). Moreover, Chu et al. (2010) had demonstrated that the Arctic soil bacterial communities are characterized by similar levels of variability, richness and phylogenetic diversity, as soils obtained from a wide range of lower latitudes. This suggests a common diversity structure within soil bacterial communities around the globe. Furthermore, Arctic soil bacterial community structure is related to local environmental factors, especially with soil acidity, similarly as it was observed for the fungal community composition in this High Arctic region (Zhang et al., 2016).

It was previously demonstrated that the soil $\mathrm{pH}$ has a fundamental impact on the bacterial communities (Shen et al., 2013), thus, the lack of significant differences between the tested samples at higher taxonomic ranks may result from a minor dissimilarity between the soil $\mathrm{pH}$ values. Lower proportions of Proteobacteria and Acidobacteria, mostly responsible for the differences between the two samples (Table 2), were observed in the soil sample under the influence of the bird colony, characterized by higher acidity, whereas the share of Actinobacteria and Chlorofelxi was higher under more alkaline conditions, i.e., in the control area (Figure 2). According to our observations, the abundance of Proteobacteria was lower under more alkaline conditions, although abundance of Alphaproteobacteria was similar in both tested soil samples. We also observed a large disproportion in the contribution of Betaproteobacteria in the total share of bacterial communities in regard to different soil $\mathrm{pH}$ values.

Kim et al. (2014) had shown that the Alphaproteobacteria share decreases with the depth of the soil layer, while other researchers had demonstrated that these bacteria prefer a nutrient rich environment (Nemerguta et al., 2010) resulting from additional nitrogen input (Fierer et al., 2012). Our physicochemical analysis revealed a considerably higher concentration of nitrogen in the soil sample from the bird colony area when compared to the control sample, which is also consisted with previous analysis (Zwolicki et al., 2013), but despite that fact, the share of Alphaproteobacteria changed only insignificantly.

Some of bacteria from the Actinobacteria phylum are able to efficiently fix nitrogen available in the air and presence of such a functional bacterial group in a soil with permanent deficits in nitrogen is comprehensible. Thus, this group can be of a high importance in the area with the constant lack of nutrition and/or when the high loads of nutrient deposition in the area of the bird colony are not fully used and are washed away by the thawing snow at the end of winter (Skrzypek et al., 2015). Therefore, reduction in the Actinobacteria abundance in the soil samples 
TABLE 2 | Average dissimilarity between the sample A under the little auk colony and sample C as the control sample compared by SIMPER analysis based on the Bray-Curtis similarity measure at the phylum level.

\begin{tabular}{|c|c|c|c|c|c|}
\hline Phylum & $A(\%)$ & C (\%) & Av. dissimilarity & Contribution (\%) & Cumulative (\%) \\
\hline Actinobacteria & 15.7 & 33.3 & 8.8 & 39.3 & 39.3 \\
\hline Proteobacteria & 26 & 15.5 & 5.3 & 23.6 & 63 \\
\hline Acidobacteria & 18.8 & 14.5 & 2.2 & 9.8 & 72.7 \\
\hline Verrucomicrobia & 8.1 & 4.2 & 2 & 8.9 & 81.6 \\
\hline Chloroflexi & 11.9 & 15.8 & 1.9 & 8.7 & 90.3 \\
\hline Nitrospirae & 4.3 & 1.7 & 1.3 & 5.8 & 96 \\
\hline Cyanobacteria & 0.1 & 0.6 & 0.2 & 1 & 97.1 \\
\hline Gemmatimonadetes & 6.5 & 6.2 & 0.1 & 0.6 & 97.7 \\
\hline OD1 & 0.4 & 0.2 & 0.1 & 0.5 & 98.2 \\
\hline Firmicutes & 0.6 & 0.4 & 0.1 & 0.4 & 98.7 \\
\hline Armatimonadetes & 0.1 & 0.2 & 0 & 0.2 & 98.9 \\
\hline WS3 & 0.1 & 0.2 & 0 & 0.2 & 99.1 \\
\hline TM7 & 0.1 & 0.1 & 0 & 0.2 & 99.2 \\
\hline OP11 & 0.1 & 0 & 0 & 0.1 & 99.3 \\
\hline Elusimicrobia & 0.2 & 0.2 & 0 & 0.1 & 99.5 \\
\hline WPS-2 & 0 & 0 & 0 & 0.1 & 99.5 \\
\hline Bacteroidetes & 3 & 3 & 0 & 0.1 & 99.6 \\
\hline Fibrobacteres & 0 & 0 & 0 & 0.1 & 99.6 \\
\hline Unknown & 0 & 0 & 0 & 0 & 99.7 \\
\hline WS4 & 0 & 0 & 0 & 0 & 99.7 \\
\hline Spirochaetes & 0 & 0 & 0 & 0 & 99.7 \\
\hline FBP & 0 & 0 & 0 & 0 & 99.8 \\
\hline $\mathrm{BRC} 1$ & 0 & 0 & 0 & 0 & 99.8 \\
\hline Chlorobi & 0.2 & 0.2 & 0 & 0 & 99.8 \\
\hline WS2 & 0.1 & 0 & 0 & 0 & 99.9 \\
\hline Planctomycetes & 3.1 & 3.1 & 0 & 0 & 99.9 \\
\hline NKB19 & 0 & 0 & 0 & 0 & 99.9 \\
\hline BHI80-139 & 0 & 0 & 0 & 0 & 99.9 \\
\hline OP3 & 0 & 0 & 0 & 0 & 100 \\
\hline TM6 & 0.1 & 0 & 0 & 0 & 100 \\
\hline GNO2 & 0 & 0 & 0 & 0 & 100 \\
\hline AD3 & 0.3 & 0.3 & 0 & 0 & 100 \\
\hline Lentisphaerae & 0 & 0 & 0 & 0 & 100 \\
\hline Chlamydiae & 0 & 0 & 0 & 0 & 100 \\
\hline GNO4 & 0 & 0 & 0 & 0 & 100 \\
\hline PAUC34f & 0 & 0 & 0 & 0 & 100 \\
\hline [Thermi] & 0 & 0 & 0 & 0 & 100 \\
\hline
\end{tabular}

impacted by the bird colony seems only natural in the context of a high amount of guano deposition and in consequence of a high nitrogen content. Koyama et al. (2014) reported that fertilization reduces the abundance of Actinobacteria in the soil, at the phylum level, while Kim et al. (2014) had shown that the abundance of Actinobacteria can be also related to the soil $\mathrm{pH}$ values. In the study presented here, we observe that within the dominant Actinobacteria phylum, the Thermoleophilia, and Actinobacteria classes are more abundant at higher soil $\mathrm{pH}$ values (Figure 3; Supplementary Table 1), although the abundance of the whole phylum is lower.
Winsley et al. (2014) analyzed 225 soil samples spanning the Arctic and Antarctic, for the presence of prevalent bacterial candidate division TM7. These phyla were found in nearly half of the tested samples, in the range of 0.05$2.23 \%$ in the total microbial community. In our study, the TM7 phyla constituted $0.08 \%$ of the total microbial community in the sample in sample from colony, and $0.15 \%$ in control sample. The role of these bacteria, as a candidate division, is still unclear since they remain uncultivable, however, they are commonly found in environmental samples. 


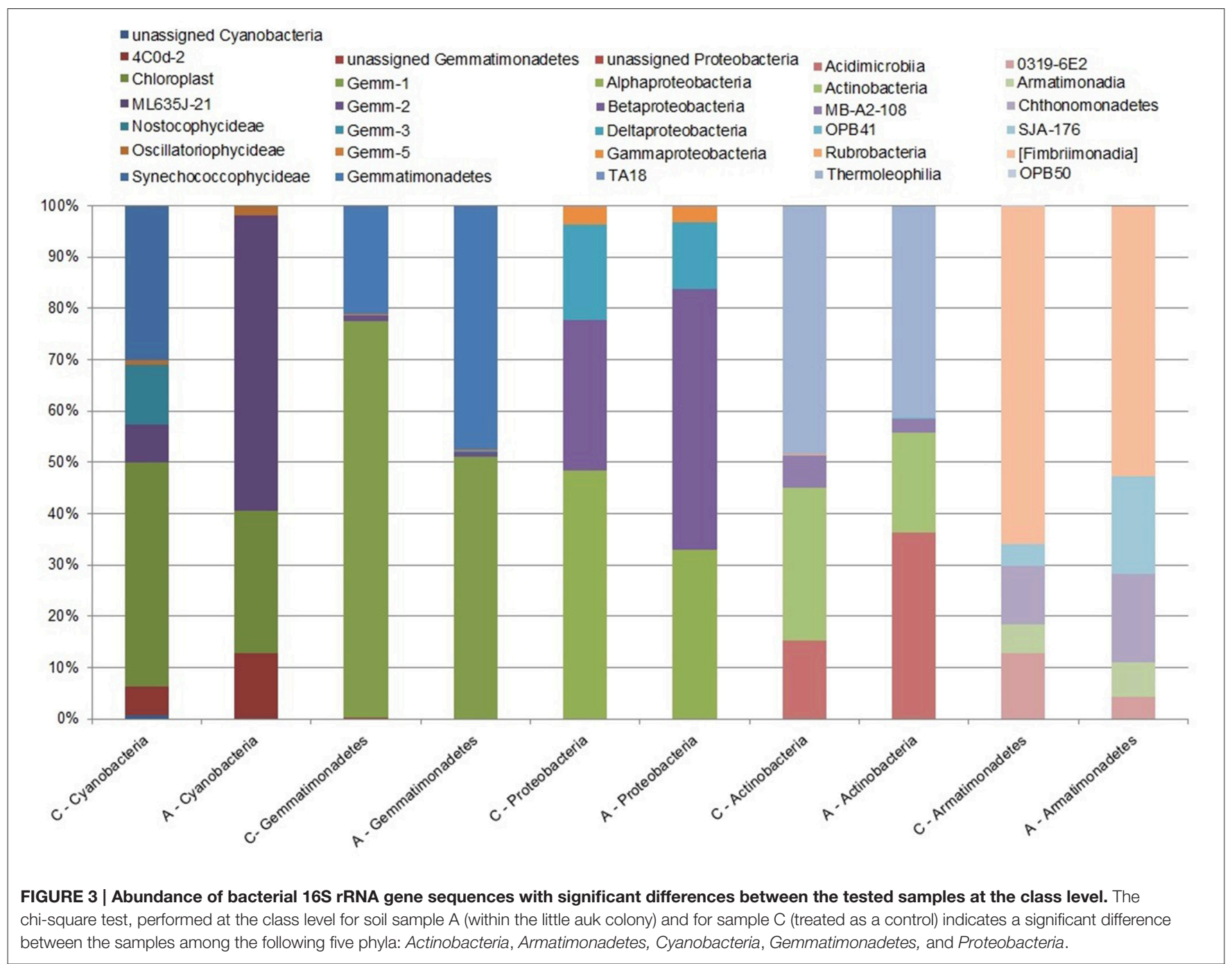

In this study, despite differences in the soil's physicochemical features, no significant differences were revealed at the phylum level of bacterial structure communities between both tested samples. Similar results were demonstrated for the Ross Sea region of Antarctica in case of the ornithogenic soils collected from land within the Adèlie Penguin rookeries (Aislabie et al., 2009). These results had shown that despite relatively high nutrient levels and high microbial biomass, the bacterial communities of ornithogenic soils were not more diverse than those of mineral soils in the Ross Sea region of Antarctica. Even though the study presented here and (Aislabie et al., 2009) were performed with the use of completely different tools and analyses, and therefore they cannot be directly compared, they arrived at the same conclusion, i.e., that a change in the soil physicochemical features due to vicinity of a seabird colony has no substantial impact on the high taxonomic ranks of bacterial structure itself, although a limited number of phyla may still be impacted. The presence of the little auk colony, which influenced the soil $\mathrm{pH}$ and nitrogen distribution, impacted only several of the phyla, like Actinobacteria and
Proteobacteria. Additional analysis, performed at the class level for each phylum, displayed significant differences between the samples for five of the phyla, inter alia Proteobacteria. Although, this phylum, together with Actinobacteria, was in the most part responsible for the differences between both tested samples, we were able to observe only minor difference at a class level.

Acidification of the soil may have a strong impact on arctic soil bacterial communities, as determined by local environmental factors (Chu et al., 2010). Our results for high taxonomic level analysis suggest that the presence of the little auk colony, which in general had influenced the soil physicochemical features (but mostly nitrogen distribution), impacts only some of the bacterial phyla, for e.g., Actinobacteria and Proteobacteria. When the analysis was carried out at the class level for each phylum, significant differences between the samples were observed for five phyla: Actinobacteria, Armatimonadetes, Cyanobacteria, Gemmatimonadetes, and Proteobacteria, wherein Armatimonadetes and Cyanobacteria accounted together for less than $1 \%$ of the total population share. Nevertheless, more 
analyses should be performed concerning not only a larger number of soil transects and a larger number of the tested samples from this particular colony, but they also should encompass other seabird colonies.

\section{AUTHOR CONTRIBUTIONS}

SZ performed DNA isolation, sequencing data analysis, wrote the manuscript, took part in planning of the study, and discussion; DK performed statistical data analysis, helped in writing the manuscript, and in sample collection; LS, MŁ, and JŁ helped in writing the manuscript and took part in planning of the study and discussions.

\section{ACKNOWLEDGMENTS}

This work was in large part supported by the National Science Center, Poland (grant no. 2011/01/D/NZ2/04817). The samples were collected while conducting a research project supported by the National Science Center (grant no. 2011/01/N/NZ8/04569). We are grateful to Mateusz Barcikowski for participation in the sample collection.

\section{REFERENCES}

Aislabie, J., Jordan, S., Ayton, J., Klassen, J. L., Barker, G. M., and Turner, S. (2009). Bacterial diversity associated with ornithogenic soil of the Ross Sea region, Antarctica. Can. J. Microbiol. 55, 21-36. doi: 10.1139/W08-126

Aronesty, E. (2011). Command-Line Tools for Processing Biological Sequencing Data. Durham, NC: Ea-utils.

Bray, J. R., and Curtis, J. T. (1957). An ordination of upland forest communities of southern Wisconsin. Ecol. Monogr. 27, 325-349. doi: 10.2307/1942268

Caporaso, J. G., Kuczynski, J., Stombaugh, J., Bittinger, K., Bushman, F. D., Costello, E. K., et al. (2010). QIIME allows analysis of highthroughput community sequencing data. Nat. Methods 7, 335-336. doi: 10.1038/nmeth.f.303

Chu, H., Fierer, N., Lauber, C. L., Caporaso, J. G., Knight, R., and Grogan, P. (2010). Soil bacterial diversity in the Arctic is not fundamentally different from that found in other biomes. Environ. Microbiol. 12, 2998-3006. doi: $10.1111 / j .1462-2920.2010 .02277 . x$

Clarke, K. R. (1993). Non-parametric multivariate analysis of changes in community structure. Aust. J. Ecol. 18, 117-143. doi: 10.1111/j.14429993.1993.tb00438.x

Croll, D. A., Maron, J. L., Estes, J. A., Danner, E. M., and Byrd, G. V. (2005). Introduced predators transform subarctic islands from grassland to tundra. Science 307, 1959-1961. doi: 10.1126/science. 1108485

Edgar, R. C. (2010). Search and clustering orders of magnitude faster than BLAST. Bioinformatics 26, 2460-2461. doi: 10.1093/bioinformatics/btq461

Fierer, N., Lauber, C. L., Ramirez, K. S., Zaneveld, J., Bradford, M. A., and Knight, R. (2012). Comparative metagenomic, phylogenetic and physiological analyses of soil microbial communities across nitrogen gradients. ISME J. 6, 1007-1017. doi: 10.1038/ismej.2011.159

Haas, B., Gevers, D., Earl, A. M., Feldgarden, M., Ward, D. V., Giannoukos, G., et al. (2011). Chimeric 16S rRNA sequence formation and detection in Sanger and 454-pyrosequenced PCR amplicons. Genome Res. 21, 494-504. doi: 10.1101/gr.112730.110

Hammer, Ø., Harper, D. A. T., and Ryan, P. D. (2001). PAST: Paleontological statistics software package for education and data analysis. Palaeontol. Electron. $4,1-9$.

Isaksen, K. (1995). "The breeding population of little auk (Alle alle) in colonies in Hornsund and Northwestern Spitsbergen," in Seabird Populations in the

\section{SUPPLEMENTARY MATERIAL}

The Supplementary Material for this article can be found online at: http://journal.frontiersin.org/article/10.3389/fmicb. 2016.01298

Presentation 1 | Detailed taxonomic analyses for different ranks in the two tested soil samples. Sunburst charts show the relative abundance of the bacterial 16S rRNA gene sequences for each soil sample, at different taxonomic levels. The first level of the sunburst chart represents all phyla present in a particular sample; the next levels represent the class, order, family, and genus, respectively (The most suitable browser is Firefox, html data are available under the following link: https://www.dropbox.com/sh/u6x3dtmoohkkrja/ AADQScCONd5Iry6KX84JFuxua?dl=0.

Supplementary Figure 1 | Rarefaction analysis of the tested soil samples based on the chao1 measure.

Supplementary Table 1 | Detailed taxonomic analyses for different ranks in the tested soil samples. Table shows the relative abundance of bacterial 16S rRNA gene sequences for each tested soil sample ( $\mathrm{A}$ and $\mathrm{C}$ ), at different taxonomic levels.

Supplementary Table 2 | Differences between sample A (under the influence of the little auk colony) and sample $C$ (the control sample) at the class level within each phylum, compared by chi-square test analysis.

Northern Barents Sea. Nor Polarinst Medd, Vol. 135, eds K. Isak-sen and V. Bakken (Oslo: Norsk Polarinstitutt), 49-57.

Janssen, P. H. (2006). Identifying the dominant soil bacterial taxa in libraries of $16 \mathrm{~S}$ rRNA and 16S rRNA genes. Appl. Environ. Microb. 72, 1719-1728. doi: 10.1128/AEM.72.3.1719-1728.2006

Kim, H. M., Jung, J. Y., Yergeau, E., Hwang, C. Y., Hinzman, L., Nam, S., et al. (2014). Bacterial community structure and soil properties of a subarctic tundra soil in Council, Alaska. FEMS Microbiol. Ecol. 89, 465-475. doi: 10.1111/15746941.12362

Klindworth, A., Pruesse, E., Schweer, T., Peplies, J., Quast, C., Horn, M., et al. (2013). Evaluation of general 16S ribosomal RNA gene PCR primers for classical and next-generation sequencing-based diversity studies. Nucleic Acids Res. 41:e1. doi: 10.1093/nar/gks808

Koyama, A., Wallenstein, M. D., Simpson, R. T., and Moore, J. C. (2014). Soil bacterial community composition altered by increased nutrient availability in Arctic tundra soils. Front. Microbiol. 5:516. doi: 10.3389/fmicb.2014.00516

McDonald, D., Price, M. N., Goodrich, J., Nawrocki, E. P., DeSantis, T. Z., Probst, A., et al. (2012). An improved Greengenes taxonomy with explicit ranks for ecological and evolutionary analyses of bacteria and archaea. ISME J. 6, 610-618. doi: 10.1038/ismej.2011.139

Nemerguta, D. R., Clevelandc, C. C., Wiedera, W. R., Washenbergera, C. L., and Townsenda, A. R. (2010). Plot-scale manipulations of organic matter inputs to soils correlate with shifts in microbial community composition in a lowland tropical rain forest. Soil Biol. Biochem. 42, 2153-2160. doi: 10.1016/j.soilbio.2010.08.011

Neufeld, J. D., and Mohn, W. W. (2005). Unexpectedly high bacterial diversity in arctic tundra relative to boreal forest soils, revealed by serial analysis of ribosomal sequence tags. Appl. Environ. Microbiol. 71, 5710-5718. doi: 10.1128/AEM.71.10.5710-5718.2005

Puczko, M., and Stempniewicz, L. (2013). "Geographical environment in the vicinity of the Stanisław Siedlecki Polish Polar Station in Hornsund. Birds and mammals," in Ancient and Modern Geoecosystems of Spitsbergen, eds Z. Zwolinski, A. Kostrzewski, and M. Pulina (Poznan: Bogucki Wydawnictwo Naukowe), 81-84.

Shen, C., Xiong, J., Zhang, H., Feng, Y., Lin, X., Li, X., et al. (2013). Soil pH drives the spatial distribution of bacterial communities along elevation on Changbai Mountain. Soil Biol. Biochem. 57, 204-211. doi: 10.1016/j.soilbio.2012. 07.013 
Skrzypek, G., Wojtuñ B., Richter, D., Jakubas, D., Wojczulanis-Jakubas, K., and Samecka-Cymerman, A. (2015). Diversification of nitrogen sources in various Tundra vegetation types in the high Arctic. PLoS ONE 10:e0136536. doi: 10.1371/journal.pone.0136536

Stempniewicz, L. (2001). Little auk Alle alle. J. Birds West. Palearctic 3, 175-120.

Stempniewicz, L., Błachowiak-Samołyk, K., and Wêsławski, J. M. (2007). Impact of climate change on zooplankton communities, seabird populations and arctic terrestrial ecosystem-a scenario. Deep Sea Res. 54, 2934-2945. doi: 10.1016/j.dsr2.2007.08.012

Winsley, T. J., Snape, I., McKinlay, J., Stark, J., van Dorst, J. M., Ji, M., et al. (2014). The ecological controls on the prevalence of candidate division TM7 in polar regions. Front. Microbiol. 5:345. doi: 10.3389/fmicb.2014.00345

Wojciechowska, A., Zwolicki, A., Barcikowska, A., and Stempniewicz, L. (2015). The structure of Cochlearia groenlandica population along the bird colony influence gradient (Hornsund, Spitsbergen). Polar Biol. 38, 1919-1930. doi: 10.1007/s00300-015-1755-3

Zawierucha, K., Zmudczyñska-Skarbek, K., Kaczmarek, Ł., and WojczulanisJakubas, K. (2015). The influence of a seabird colony on abundance and species composition of water bears (Tardigrada) in Hornsund (Spitsbergen, Arctic). Polar Biol. 39, 713-723. doi: 10.1007/s00300-015-1827-4

Zelickman, E. A., and Golovkin, A. N. (1972). Composition, structure, and productivity of neritic plankton communities near the bird colonies of the northern shores of Novaya Zemlya. Mar. Biol. 17, 265-274. doi: 10.1007/BF00366302

Zhang, T., Wang, N.-F., Liu, H.-Y., Zhang, Y.-Q., and Yu, L.-Y. (2016). Soil $\mathrm{pH}$ is a key determinant of soil fungal community composition in the Ny-Ålesund Region, Svalbard (High Arctic). Front. Microbiol. 7:227. doi: 10.3389/fmicb.2016.00227

Zmudczyñska, K., Olejniczak, I., Zwolicki, A., Iliszko, L., Convey, P., and Stempniewicz, L. (2012). Influence of allochtonous nutrients delivered by colonial seabirds on soil collembolan communities on Spitsbergen. Polar Biol. 35, 1233-1245. doi: 10.1007/s00300-012-1169-4

Zmudczyñska-Skarbek, K., Balazy, P., and Kuklinski, P. (2015a). An assessment of seabird influence on Arctic coastal benthic communities. J. Mar. Syst. 144, 48-56. doi: 10.1016/j.jmarsys.2014.11.013

Zmudczyñska-Skarbek, K., Zwolick, A., Convey, P., Barcikowski, M., and Stempniewicz, L. (2015b). Is ornithogenic fertilization important for collembolan communities in Arctic terrestrial ecosystems? Polar Res. 34:25629. doi: 10.3402/polar.v34.25629

Zwolicki, A., Barcikowski, M., Barcikowski, A., Cymerski, M., Stempniewicz, L., and Convey, P. (2015). Seabird colony effects on soil properties and vegetation zonation patterns on King George Island, Maritime Antarctic. Polar Biol. 38, 1645-1655. doi: 10.1007/s00300-015-1730-z

Zwolicki, A., Zmudczyñska-Skarbek, K. M., Iliszko, L., and Stempniewicz, L. (2013). Guano deposition and nutrient enrichment in the vicinity of planktivorous and piscivorous seabird colonies in Spitsbergen. Polar Biol. 36, 363-372. doi: 10.1007/s00300-0121265-5

Conflict of Interest Statement: The authors declare that the research was conducted in the absence of any commercial or financial relationships that could be construed as a potential conflict of interest.

Copyright (c) 2016 Zielinska, Kidawa, Stempniewicz, Łoś and Łoś. This is an openaccess article distributed under the terms of the Creative Commons Attribution License (CC BY). The use, distribution or reproduction in other forums is permitted, provided the original author(s) or licensor are credited and that the original publication in this journal is cited, in accordance with accepted academic practice. No use, distribution or reproduction is permitted which does not comply with these terms. 